\title{
Editors' Note to: Predicting adult height from DNA variants in a European-Asian admixed population
}

\author{
Springer Berlin Heidelberg
}

Published online: 5 December 2019

(C) Springer-Verlag GmbH Germany, part of Springer Nature 2019

Editors' Note to: International Journal of Legal Medicine (2019) 133:1667-1679

https://doi.org/10.1007/s00414-019-02039-8

'Concerns have been raised about the ethics approval and informed consent procedures related to the research reported in this paper [1]. The paper includes the following author declarations: "The study was approved by the ethics committee of Institute of Forensic Science, Ministry of Public Security, China. All participants provided written informed consent". Editorial action will be taken as appropriate once an investigation of the concerns is complete and all parties have been given an opportunity to respond in full.'

[1] Xiaoxi Jing, Yanan Sun, Wenting Zhao, Xingjian Gao, Mi Ma, Fan Liu, Caixia Li (2019), Predicting adult height from DNA variants in a European-Asian admixed population. International Journal of Legal Medicine (2019) 133:16671679 https://doi.org/10.1007/s00414-019-02039-8

Publisher's note Springer Nature remains neutral with regard to jurisdictional claims in published maps and institutional affiliations.

\section{Springer Berlin Heidelberg}

https://www.springer.com/journal/414 